Journal of Applied Pharmaceutical Science Vol. 6 (06), pp. 123-130, June, 2016

Available online at http://www.japsonline.com

DOI: $10.7324 / \mathrm{JAPS} .2016 .60622$

ISSN 2231-3354 (cc) EY-NC-SA

\title{
Prevalence, antibiotic and oil resistance pattern of some bacterial isolates from burns
}

\author{
Mona I. Mabrouk ${ }^{1}$, Hoda Hamed El-Hendawy ${ }^{2}$, Amr Mohamad Basha ${ }^{{ }^{*}}$, Neveen Mohamed Saleh ${ }^{1}$ \\ ${ }^{1}$ Microbiology Department, National Organization of Drug Control and Research, Giza, Egypt. ${ }^{2}$ Botany and Microbiology Department, Faculty of Science, \\ Helwan University, Helwan, Egypt.
}

\begin{tabular}{l} 
ARTICLE INFO \\
\hline Article history: \\
Received on: 07/04/2016 \\
Revised on: $28 / 04 / 2016$ \\
Accepted on: $16 / 05 / 2016$ \\
Available online: $28 / 06 / 2016$ \\
\hline
\end{tabular}

Key words:

Burns, wound infection, antibiotic resistance,

cinnamon bark, thyme.

\begin{abstract}
Infection is an important cause of mortality in patients with burns. Rapid emergence of hospital pathogens and antibiotic-resistant organisms necessitate periodic evaluation of bacterial colonization patterns and antibiogram sensitivity in burn wards. Sixty isolates from wounds of burns were collected from two hospitals in Cairo, Egypt along the period of 12 months in 2013. Antibiotic sensitivity of these isolates was assessed by single disk diffusion method. Multi drug resistance percentage and the most prevalent resistance phenotype among bacterial isolates were recorded. In addition, 19 essential oils were tested against the MDR isolates. The most potent oils were analyzed by GC-MS to determine their main chemical constituents. According to microbiological and biochemical identification method, Pseudomonas aeruginosa was the most dominant organism 23 (38\%), followed by Staphylococcus aureus 16 (27\%), Klebsiella spp. 11 (18\%), Acinetobacter spp. 4 (7\%). Three isolates of Escherichia coli (5\%) and three isolates of Proteus spp. (5\%). Piperacillin-tazobactam, imipenem and linezolid antibiotics were the most effective antibiotics against Pseudomonas aeruginosa, Enterobacteriaceae and $S$. aureus isolates respectively. Cinnamon and thyme essential oils were the most potent oils against the multi drug resistant burn wound isolate. Cinnamaldehyde $(60.7 \%)$ and $\rho$-cymene $(50 \%)$ were the major chemical constituents in cinnamon and thyme essential oils, respectively. It is clear that antibiotic resistance levels are high among the examined bacterial isolates of burn wounds. This study could be useful for physician to better choice of empiric therapy. Cinnamon and thyme may be used as a promising an alternative medicine for the treatment of burn wound infections.
\end{abstract}

\section{INTRODUCTION}

Burns are damage to the skin caused by variety of nonmechanical sources including chemicals, electricity, heat, sunlight or nuclear radiation. Thermal injury is a serious type of trauma required care in a specialized units. It has been estimated that approximately 2.5 million people sustain burns of which 100,000 are hospitalized and there are around 12,000 deaths per year due to thermal injuries (Mayhall, 2003). Thermal destruction of the skin barrier and concomitant depressions of local and systemic host cellular and humoral immune responses are pivotal factors contributing to infectious complications in patients with severe burns. The burn wound surface is a protein

* Corresponding Author

Email: amr_basha_85@yahoo.com rich environment consisting of avascular necrotic tissue (eschar) that provides a favorable niche for microbial colonization and proliferation. The avascularity of the eschar results in impaired migration of host immune cells and restricts delivery of systemically administered antimicrobial agents to the area, while toxic substances released by eschar tissue impair local host immune response (Church et al., 2006). The cause of nosocomial infections in burn patients might be endogenous or exogenous. Endogenous infections are caused by organism present as part of the normal flora of the patient, while exogenous infections are acquired through exposure to the hospital environment, hospital personnel or medical devices (Samuel et al., 2010). The emergence worldwide of antimicrobial resistance among a wide variety of human bacterial and fungal burn wound pathogens, particularly nosocomial isolates, limits the available therapeutic options for effective treatment of burn wound infections (Taneja et al., 2004). 
Essential oils are very complex natural mixtures which contain about 20-60 components at quite different concentrations. They are characterized by two or three major components at fairly high concentrations (20-70\%) compared to other components present in trace amounts (Bakkali et al., 2008).

The antibacterial properties of plant essential oils have been known for many centuries. Essential oils have been found to have great effects in disrupting the bacterial membrane. It is likely due to the presence of lipophilic compounds such as cyclic hydrocarbons, terpenes and aromatics which are abundantly found in the aromatic plants (Langeveld et al., 2013).

This investigation was carried was carried out to determine which bacteria are prevalent in burn wounds and to study their antibiotic resistance pattern. Also, the role of 19 essential oils in inhibition of the growth of these antibiotic resistant bacteria was investigated.

\section{MATERIAL AND METHOD}

\section{Bacterial isolates, isolation and identification}

Collection of burn wound swabs was carried out during the period of January 2013 to December 2013 from burn units of two hospitals in Cairo; Ain-Shams University (El-Demerdash Hospital) and Cairo University (El-Kasr El-Eini- Hospital). Swabs were transported to the Department of Microbiology C Lab at National Organization for Drug Control and Research (NODCAR) and cultured immediately at the same day of arrival on blood agar and MaCconkey agar.

The plates were incubated at $37^{\circ} \mathrm{C}$ for $24 \mathrm{~h}$. Identification of bacteria were carried out according to Mahon et al. (2011), and Engelkirk \& Duben-Engelkirk (2008). Biochemical tests were performed to identify the collected isolates.

Gram-negative rods were identified by performing a series of biochemical tests; triple sugar iron agar (TSI), Indole test, Methyl red- Voges proskauer tests, Simon's citrate agar test, oxidase test, urea test and motility test. Gram-positive cocci were identified based on their gram reaction, catalase and coagulase test.

\section{Screening for antibiotic resistance}

Antibacterial susceptibility test was performed on Muller Hinton agar by standard disk diffusion method Bauer et al. (1966), following recommendation of Clinical and Laboratory Standards Institute CLSI (2006).

The tested antibiotic disks were purchased from Oxoid, UK and they included ampicillin $(10 \mu \mathrm{g})$, piperacillin $(100 \mu \mathrm{g})$, penicillin (10 units), amoxicillin/clavulanic acid $(20 / 10 \mu \mathrm{g})$, piperacillin/tazobactam $(100 / 10 \mu \mathrm{g})$, cefepime $(30 \mu \mathrm{g})$, cefotaxime $(30 \mu \mathrm{g})$, imipenem $(10 \mu \mathrm{g})$, meropenem $(10 \mu \mathrm{g})$, gentamicin $(10 \mu \mathrm{g})$, amikacin $(10 \mu \mathrm{g})$, tobramycin $(10 \mu \mathrm{g})$, ciprofloxacin $(5 \mu \mathrm{g})$, levofloxacin $(5 \mu \mathrm{g})$, trimethoprim/ sulfamethoxazole $(1.25 / 23.75$ $\mu \mathrm{g})$, aztreonam $(30 \mu \mathrm{g})$, cefoxitin $(30 \mu \mathrm{g})$, oxacillin $(30 \mu \mathrm{g})$, teicoplanin $(30 \mu \mathrm{g})$, erythromycin $(15 \mu \mathrm{g})$, tetracycline $(30 \mu \mathrm{g})$, clindamycin $(2 \mu \mathrm{g})$, and linezolid $(30 \mu \mathrm{g})$.

\section{Antibacterial activity of oils by agar well diffusion method}

The tested essential oils are listed in Table (1). These oils were selected according to Deans and Ritchie (1987) and Baser and buchbauer (2010). Essential oils were obtained from PhytoChemistry Department, National Organization for Drug Control and Research (NODCAR). Antibacterial activity of the oils against the most resistant burn wound isolates were tested by agar well diffusion method according to CLSI (2006).

Table 1: Essential oils tested

\begin{tabular}{llll}
\hline \multicolumn{1}{c}{ Essential oils } & \multicolumn{1}{c}{ Binomial name } & $\begin{array}{c}\text { Plant family } \\
\text { name }\end{array}$ & $\begin{array}{c}\text { Plant part } \\
\text { used }\end{array}$ \\
\hline Lemon oil & Citrus lemon & Rutaceae & Fruit \\
Cinnamon bark oil & Cinnamomum verum & Lauraceae & Bark \\
Garlic oil & Allium sativum & Amaryllidaceae & Bulb \\
Caraway oil & Carum carvi & Apiaceae & Fruit \\
Peppermint oil & Mentha piperita & Lamiaceae & leaves \\
Tea tree oil & Melaleuca alternifolia & Myrtaceae & leaves \\
Geranium oil & Pelargonium & Geraniaceae & leaves \\
Thyme oil & Thymus vulgaris & Lamiaceae & Leaves \\
Fennel oil & Foeniculum vulgare & Apiaceae & Seed \\
Eucalyptus oil & Eucalyptus globulus & Myrtaceae & Leaves \\
Clove & Syzygium aromaticum & Myrtaceae & Flower buds \\
Olive oil & Olea europaea & Oleaceae & Fruit \\
Camphor oil & Cinnamomum camphora & Lauraceae & Wood \\
Anise oil & Pimpinella anisum & Apiaceae & Seed \\
Orange oil & Citrus Sinensis & Rutaceae & Fruit \\
Dill oil & Anethium graveolens & Apiaceae & Seed \\
Ginger oil & Zingiber officinale & Zingiberaceae & Rhizomes \\
Moringa oil & Moringa oleifora & Moringaceae & Seed \\
Rose marry oil & Rosmarimus officinalis & Lamiaceae & Flowers \\
\hline
\end{tabular}

\section{GC- mass analysis of the most potent oils}

The most potent essential oils were analysed by gas chromatography combined with mass spectrometry (GC/MS). The $\mathrm{GC} / \mathrm{MS}$ analysis was performed using a thermo scientific, trace ultra /isq single quadrupole $\mathrm{ms}$, tg-5ms fused silica capillary column $(30 \mathrm{~m}, 0.251 \mathrm{~mm}, 0.1 \mathrm{~mm}$ film thickness). Helium gas was used as the carrier gas at a constant flow rate of $1 \mathrm{ml} / \mathrm{min}$. The injector and MS transfer line temperature was set at $280^{\circ} \mathrm{C}$. The oven temperature was programmed at an initial temperature $40^{\circ} \mathrm{C}$ (hold $3 \mathrm{~min}$ ) to $280^{\circ} \mathrm{C}$ as a final temperature at an increasing rate of $5^{\circ} \mathrm{C} / \min$ (hold $5 \mathrm{~min}$ ).

\section{RESULTS AND DISSUCION}

Nosocomial Infection is an important cause of mortality in burns, and is considers one of the most serious complications in burn patients. It has been estimated that $75 \%$ of all deaths following thermal injuries are related to infections (Mehta et al., 2007). In this study; sixty isolates were collected from burn units at two hospitals in Cairo, Egypt. Twenty isolates from Cairo University hospital and forty isolates from Ain Shams University hospital. Bacterial identification results are shown in Figure (1). 16(26.6\%) isolates were gram- positive Cocci and $44(73.3 \%)$ isolates were gram negative bacilli. these results are consistent with results reported by Kehinde et al. (2004) who reported that the rate of gram negative bacterial species isolated from burn wound was more than twice that gram positive one.

Bacterial identification results in Figure (1) shows that the most dominant bacteria was Pseudomonas aeruginosa 23 
(38\%), followed by Staphylococcus aureus 16 (27\%), Klebsiella pneumoniae 11 (18\%), Acinetobacter baumanii 4 (7\%). Escherichia coli 3 (5\%) and Proteus vulgaris 3(5\%) isolates were also detected.

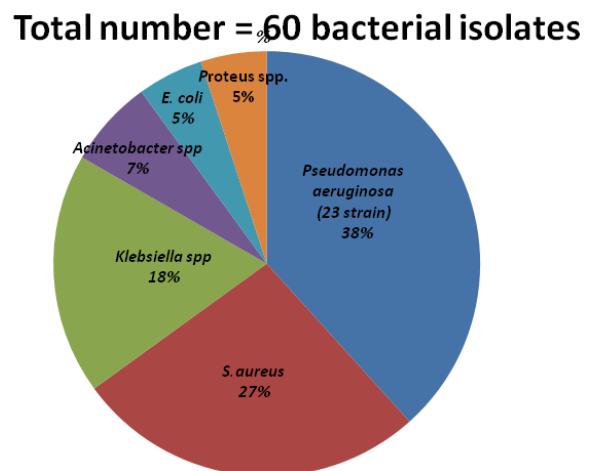

Fig. 1: Bacterial identification results

$P$. aeruginosa was found to be the most important resistant and dangerous organism in burn patient infection; Pseudomonas infection is a common complication in burn patients and contributes to their morbidity and mortality (Lari et al., 2005). $P$. aeruginosa was found to be the most common pathogen isolated from burned patients and accounted for $(38 \%)$ of the total isolates, which refer to that $P$. aeruginosa is a major factor in the etiology of burn wound infection. In many economically developing countries such as Zimbabwe (Igumbor et al., 2001), South Korea (Song et al., 2001), Jordan (Al-Akayleh, 1999), Libya (Husain et al., 1989), Nigeria (Atoyebi et al., 1992), India (Pandit et al., 1993; Revathi et al., 1998 and Kaushik et al., 2001), and Turkey (Arslan et al., 1999 and Oncul et al., 2002), P. aeruginosa was reported to be the most common bacteria among burn patients. Few burn centers in Canada and the USA, (Shankowsky et al., 1994) and France (Cremer et al., 1996), have been reported $P$. aeruginosa as an important microorganism in burn units. Other studies reported the same result; (Nagoba et al., 1999; Nasser et al., 2003; Agnihotri et al., 2004; Ekrami and Kalantar, 2007 and Rajput et al., 2008). In contrast to our study, some reports indicated that $P$. aeruginosa was not the major causative pathogen in burn wound infections; Vindenes and Bjerknes (1995) found that $P$. aeruginosa represent only $(10.9 \%)$ out of the total number of isolates.

Staphylococcus aureus is a versatile human pathogen. It was the predominant cause of burn wound infection and still persists as an important pathogen, the second most commonest isolate in our study was $S$. aureus with incidence rate $(27 \%)$, this result was similar to that of Song et al. (2001) who reported that $S$. aureus was the second pathogen isolated in their burn units, Altoparlak et al. (2004) was observed that S. aureus $(30.4 \%)$ was the second frequent pathogen isolated in burns unit, Ramakrishnan et al. (2006) studied a period of 6 years infections in burn patients and found that $S$. aureus with incidence rate (37\%) forming the second main organism. Rajput et al. (2008) observed that the second most common isolate was $S$. aureus with incidence rate
(19.29\%). In contrast to our results other studies found that $S$. aureus was the most common isolate in burn wound infection (Komolafe et al., 2002 and Imran et al., 2007).

Klebsiella pneumoniae was recovered in a frequency rate of (18\%), Nagesha et al. (1996), found that Klebsiella pneumoniae was the third common pathogen with an incidence rate of $(12 \%)$. Also Rajput et al. (2008) showed that Klebsiella species was the third commonest pathogen with incidence rate $(11.4 \%)$. In contrast to our results; Ozumba and Jiburum (2000) observed the prevalence of $K$. pneumonia with incidence rate $(26.7 \%)$.

In our study; Escherichia coli and Proteus vulgaris species were accounted for $5 \%$ of the total isolates. The low incidence of $E$. coli and P. vulgaris species is in conformity with other previous studies. (Ozumba and Jiburum, 2000; Kehinde et al., 2004; Rajput et al., 2008; Agnihotri et al., 2004 and Guggenheim et al., 2009).

Antibiotic sensitivity test is important for epidemiological and clinical purposes. Incresing antimicrobial reisstance among burn wound isolates is a matter of concern, with limited treamtment options available for resistant strains (Aruna et al., 2010).

Figure (2) indicates the antimicrobial resistance level of $S$. aureus isolates to different antibiotics. The obtained results clearly showed that $S$. aureus was highly resistant to the most of the tested antibiotics. S. aureus was completely resistant to oxacillin, penicillin, and cefoxitin with resistance rate $(100 \%)$, these results are consistent with that obtained from a study conducted by $\mathrm{Xu}$ et al (2013). In the present study, all the staphylococci isolates were methicillin-resistant staphylococci (MRSA), similar studies reported the higher incidence of MRSA in burn infections (Song et al., 2001 and Montazeri et al., 2013), and supports the fact that there was increasing evidence that MRSA has become a significant problem.

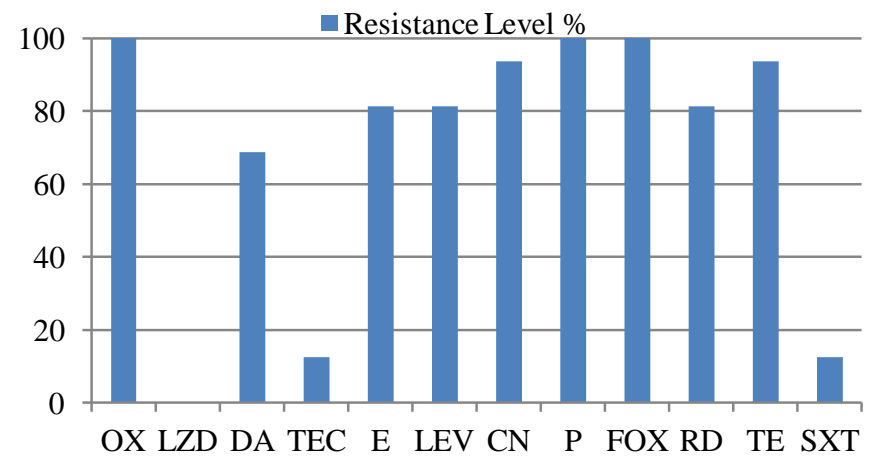

Fig. 2: Antibiotic resistance level of $S$. aureus isolates.

Keys : OX (Oxacillin), LZD (linezolid), DA (Clindamycin), TEC (Teicoplanin), E (Erythromycin), LEV (Levofloxacin), CN (Gentamicin), P (Penicillin), FOX (Cefoxitin), RD (Rifampicin), SXT (Trimethoprimsulphamethoxazole), TE (Tetracycline).

In this study; linezolid was found to be the most effective antibiotic against $S$. aureus isolates. this finding is consistent with many other reports (Manjula et al., 2007; Dash et al., 2013; Vaijnath, 2013 and $\mathrm{Xu}$ et al., 2013). Most of S. aureus isolates 
were sensitive to trimethoprim-sulphamethoxazole and teicoplanin, a study conducted by Song et al. (2001) reported that trimethoprim-sulphamethoxazole was very effective against $S$. aureus isolates with resistance level (10\%). In additon; Altoparlak et al. (2004) recorded higher susceptibility of $S$. aureus to teicoplanin with only $(2.7 \%)$ of the isolates were resistant to this antibiotic.

The percentage of resistance level of gram negative isolates to antibiotics is presented in Figure (3). The most effective drugs against $P$. aeruginosa were piperacillin/tazobactam and piperacillin $21.7 \%$, this result is in a conformity with the result of other studies in which piperacillin/tazobactam recorded the least resistance (Dash et al., 2013 and Vaijnath, 2013). Imipenem antibiotic was the second effective drug against $P$. aeruginosa isolates. Dash et al. (2013) reported the same results; low resistance pattern was shown towards piperacillin/tazobactam, piperacillin and imipenem. this could be attributed to its restricted use because of highr cost or limited availability. Resistance rate of P.aeruginosa to meropenem was $69 \%$, in contrast to our study, Bayram et al. (2013) showed that merpoenem was more effective against $P$. aeruginosa with resistant rate 19\%. Another study conducted with Rezaei et al. (2011) reported that relative frequency of resistance to meropenem antibiotic was $18.5 \%$.

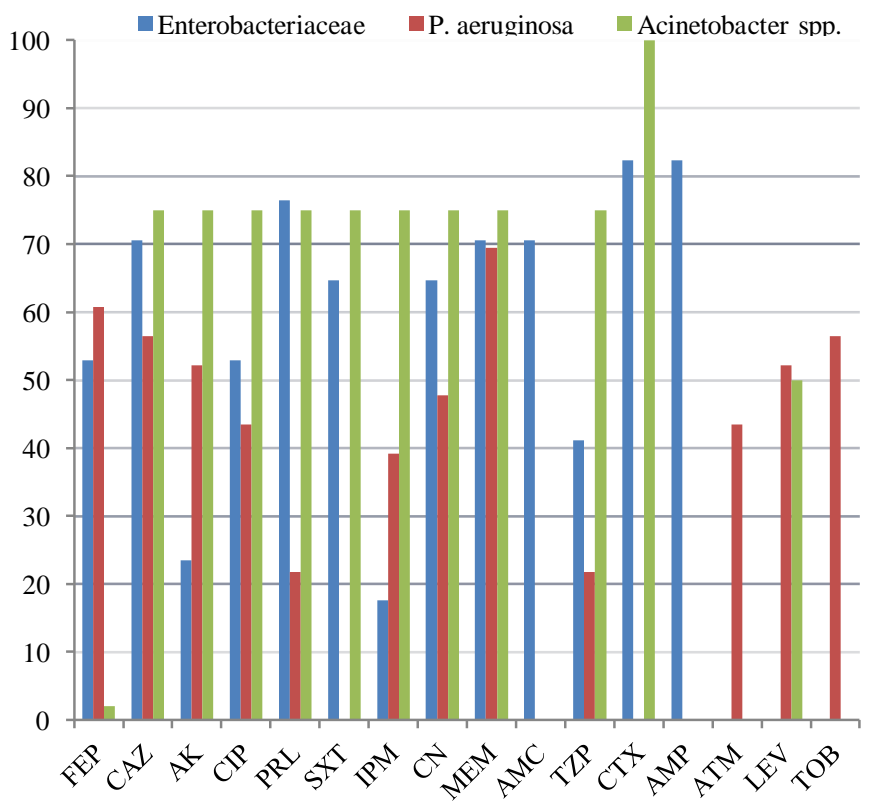

Fig. 3: Antibiotic resistance level of gram negative isolates.

Keys: FEP (cefepime), CAZ (ceftazidime), AK (Amikacin), CIP (ciprofloxacin), PRL (piperacillin), SXT (Trimethoprim-sulphamethoxazole), IPM (imipenem), CN (gentamicin), MEM (Meropenem), AMC (Amoxicillinclavulanic acid), TZP ((Piperacillin- tazobactam), CTX (cefotaxime), AMP (ampicillin), ATM (aztreonam), LEV (levofloxacin), TOB ( tobramycin).

The least effective antibiotics against Enterobacteriaceae were ampicillin and cefotaxime with resistance rate more than $82 \%$, similar result was reported by another study (Mohammedaman et al., 2014). Other study reported lower resistance rate for cefotaxime with Klebsiella spp. (59.5\%) and E. coli $(23.1 \%)$ Bhat and Vasaikar (2010). Imipenem was the most effective antibiotic against Enterobacteriaceae followed by amikacin, this result was in agreement with another study reported by Bhat and Vasaikar (2010).

Most of Acinetobacter baumanii showed high resistance level to many of tested antibiotics. This result was in agreement with that of (Song et al., 2001; Singh et al., 2003 and Rezaei et al., 2011).

Other studies reported moderate resistance level to piperacillin/ tazobactam and lower resistance level to imipenem and meropenem (De Marcedo \& Santos, 2005 and Guggenheim et al., 2009).

The overall rate of multiple drug resistance of the isolates in this study was $82 \%$, other previous study reported that the multi-drug resistance was found in $85 \%$ of the total burn isolates (Mohammedaman et al., 2014). The high antibiotic resistance of burn wound pathogens is an alarming trend that necessitates following a strict antibiotic policy to minimize resistance (Abbas et al., 2013).

Table 2: Resistance profile of S.aureus isolates

\begin{tabular}{|c|c|}
\hline \multicolumn{2}{|l|}{ Resistance profile } \\
\hline Antibiotics (n=12) & Isolates no. \\
\hline Resistant to 3 antibiotics & \multirow{2}{*}{14} \\
\hline $\mathrm{OX}, \mathrm{P}, \mathrm{FOX}$ & \\
\hline MDR isolates & \\
\hline Resistant to 6 antibiotics & \multirow{2}{*}{33} \\
\hline $\mathrm{OX}, \mathrm{CN}, \mathrm{P}, \mathrm{FOX}, \mathrm{RD}, \mathrm{TE}$ & \\
\hline Resistant to 7 antibiotics & \multirow{2}{*}{1} \\
\hline OX, LEV, CN, P, FOX, RD, TE & \\
\hline OX, E, CN, P, FOX, SXT, TE & 51 \\
\hline Resistant to 8 antibiotics & \multirow{2}{*}{46} \\
\hline OX, E, LEV, CN, P, FOX, SXT, TE & \\
\hline Resistant to 9 antibiotics & \multirow{2}{*}{$\begin{array}{l}59,55,54,53,41,40, \\
39,37,34\end{array}$} \\
\hline OX, DA, E, LEV, CN, P, FOX, RD, TE & \\
\hline Resistant to 10 antibiotics & \multirow{2}{*}{58,5} \\
\hline OX, DA, TEC, E, LEV, CN, P, FOX, RD, TE & \\
\hline $\begin{array}{l}\text { Keys : OX (Oxacillin), LZD (linezolid), } \\
\text { (Teicoplanin), E (Erythromycin), LEV (Levofl } \\
\text { (Penicillin), FOX (Cefoxitin), RD (Rifam } \\
\text { sulphamethoxazole), TE (Tetracycline) }\end{array}$ & $\begin{array}{l}\text { DA (Clindamicin), TEC } \\
\text { racin), CN (Gentamicin), P } \\
\text { i), SXT (Trimethoprim- }\end{array}$ \\
\hline
\end{tabular}

Table (2) shows that the most prevalent resistance profile in $S$. aureus isolates is (OX, DA, E, LEV, CN, P, FOX, RD, TE) which was detected in 8 isolates, followed by (OX, DA, TEC, E, LEV, CN, P, FOX, RD, TE) which was detected in two isolates. Resistance to 10 antibiotics was exhibited by isolates no. 58 and 5 .

Table (3) shows that the most prevalent resistance profile in Enterobacteriaceae is (CAZ, PRL, SXT, CN, MEM, AMC, CTX, AMP) which was detected in 4 isolates, followed by (FEP, CAZ, CIP, PRL, SXT, CN, MEM, AMC, TZP, CTX, AMP) which was detected in two isolates. Resistance to 12 or 13 antibiotics was detected in isolates no. 9, 10, and 35 .

Table (4) showed that the most prevalent resistance profile in $P$. aeruginosa isolates is (ATM, CAZ, CIP, TOB, LEV, MEM, CN, FEP, AK) which was exhibited in 3 isolates, followed by resistance profile (IPM, TZP, ATM, PRL, CAZ, MEM, FEP, AK) which was detected by two isolates. Resistance to 11 or 12 antibiotics was detected in isolates no. 42, 28 and 12 . 
Table 3: Resistance profile of Enterobacteriaceae isolates

Resistance profile

Antibiotics (n=13)

MDR isolates

Resistant to 5 antibiotics

FEP, PRL, MEM, CTX, AMP

Resistant to 7 antibiotics

FEP, CAZ, CIP, SXT, CN, CTX, AMP

Resistant to 8 antibiotics

CAZ, PRL, SXT, CN, MEM, AMC, CTX, AMP

Resistant to 9 antibiotics

FEP, CAZ, CIP, PRL, SXT, CN, AMC, CTX, AMP

FEP, CAZ, CIP, PRL, MEM, AMC, TZP, CTX, AMP

Resistant to 11 antibiotics

CAZ, AK, CIP, PRL, SXT, CN, MEM, AMC, TZP, CTX, AMP

FEP, CAZ, CIP, PRL, SXT, CN, MEM, AMC, TZP, CTX, AMP

Resistant to 12 antibiotics

FEP, AK, CIP, PRL, SXT, IPM, CN, MEM, AMC, TZP, CTX, AMP

FEP, CAZ, AK,CIP, PRL, SXT, IPM, MEM, AMC, TZP, CTX, AMP

Resistant to 13 antibiotics

FEP, CAZ, AK, CIP, PRL, SXT, IPM, CN, MEM, AMC,TZP,CTX, AMP

Isolates no.

3

2

$21,23,24,26$

15

17

49

31,32

10

35

9

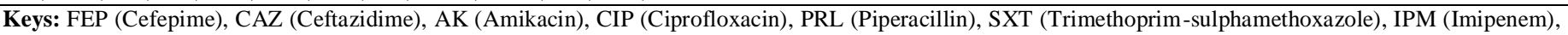

CN(Gentamicin), MEM (Meropenem), AMC (Amoxicillin-clavulanic acid), TZP (Piperacillin-tazobactam), CTX (Cefotaxime), AMP (Ampicillin).

Table 4: Resistance profile of Pseudomonas aeruginosa isolates

\begin{tabular}{|c|c|}
\hline \multicolumn{2}{|l|}{ Resistance profile } \\
\hline Antibiotics (n=12) & Isolates no. \\
\hline $\begin{array}{l}\text { Resistant to } 1 \text { antibiotics } \\
\text { CN }\end{array}$ & 44 \\
\hline ATM & 60 \\
\hline $\begin{array}{l}\text { Resistant to } 2 \text { antibiotics } \\
\text { IPM, MEM }\end{array}$ & 57 \\
\hline \multicolumn{2}{|l|}{ MDR isolates } \\
\hline $\begin{array}{l}\text { Resistant to } 3 \text { antibiotics } \\
\text { TOB, LEV, MEM }\end{array}$ & 22 \\
\hline CIP, TOB, LEV & 38 \\
\hline $\begin{array}{l}\text { Resistant to } 4 \text { antibiotics } \\
\text { CAZ, TOB, MEM, FEP }\end{array}$ & 8 \\
\hline IPM, MEM, FEP, AK & 56 \\
\hline $\begin{array}{l}\text { Resistant to } 6 \text { antibiotics } \\
\text { IPM, CAZ, TOB, MEM, FEP, AK }\end{array}$ & 13 \\
\hline ATM, CAZ, TOB, LEV, MEM, FEP & 36 \\
\hline $\begin{array}{l}\text { Resistant to } 7 \text { antibiotics } \\
\text { IPM, CIP, TOB, LEV, MEM, CN, AK }\end{array}$ & 45 \\
\hline $\begin{array}{l}\text { Resistant to } 8 \text { antibiotics } \\
\text { ATM, CAZ, CIP, TOB, LEV, CN, FEP, AK }\end{array}$ & 4 \\
\hline IPM, TZP, ATM, PRL, CAZ, MEM, FEP, AK & 16,20 \\
\hline IPM, ATM, CAZ, CIP, LEV, MEM, CN, FEP & 47 \\
\hline $\begin{array}{l}\text { Resistant to } 9 \text { antibiotics } \\
\text { ATM, CAZ, CIP, TOB, LEV, MEM, CN, FEP, AK }\end{array}$ & $11,27,30$ \\
\hline $\begin{array}{l}\text { Resistant to } 11 \text { antibiotics } \\
\text { IPM, TZP, PRL, CAZ, CIP, TOB, LEV, MEM, CN, FEP, AK }\end{array}$ & 28 \\
\hline IPM, TZP, PRL, CAZ, CIP, TOB, LEV, MEM, CN, FEP, AK & 12 \\
\hline $\begin{array}{l}\text { Resistant to } 12 \text { antibiotics } \\
\text { IPM, TZP, ATM, PRL, CAZ, CIP, TOB, LEV, MEM, CN, FEP, AK }\end{array}$ & 42 \\
\hline
\end{tabular}

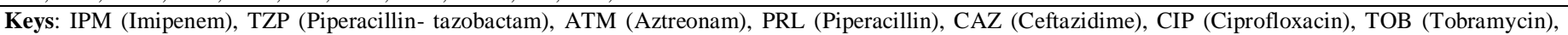

LEV (Levofloxacin), MEM (Meropenem), CN (Gentamicin), FEP (Cefepime), AK(Amikacin)

Table (5) shows that the resistance profile (AK, CAZ, TZP, SXT, CN, IPM, LEV, PRL, CIP, MEM, CTX) were observed in three of four A. baumanii isolates; isolates no. 7, 48 and 50. Overall; multi drug resistance (MDR) was found in 49 $(82 \%)$ of the isolates, $(94 \%)$ of the gram positive isolates showed multi drug resistance, $(77.2 \%)$ of gram negative isolates showed MDR. During the last few years, medicinal plants have attracted the attention of pharmaceutical and scientific communities, and evidence has demonstrated the promising potential of antimicrobial plant-derived substances (Nash et al., 2011 and Osbourn, 1996). In this study, the antibacterial activity of different plant oil extracts were tested against the most antibiotic resistant burn wound isolates that is listed in Table (6). The obtained results revealed that thyme oil is the most effective followed by cinnamon oil and eucalyptus oil, peppermint oil and clove oil showed a moderate activity against $S$. aureus isolates, this findings are quite similar to that reported by Yousef and Tawil (1980), Janssen et al. (1986), Hili et al. (1997), Singh et al. (2007). 
Table 5: Resistance profile of Acinetobacter baumanii isolates.

\begin{tabular}{|c|c|c|c|c|c|c|c|c|c|c|c|c|c|c|c|}
\hline \multicolumn{16}{|l|}{ Resistance profile } \\
\hline \multicolumn{10}{|l|}{ Antibiotics (n=11) } & \multicolumn{6}{|c|}{ Isolates no. } \\
\hline \multicolumn{10}{|c|}{$\begin{array}{l}\text { Resistant to } 1 \text { antibiotic } \\
\text { CTX }\end{array}$} & \multicolumn{6}{|c|}{$\mathrm{Ac}_{29}$} \\
\hline \multicolumn{16}{|c|}{ MDR strains } \\
\hline \multicolumn{10}{|c|}{$\begin{array}{l}\text { Resistant to } 11 \text { antibiotics } \\
\text { AK,CAZ,TZP,SXT,CN,IPM,LEV,PRL,CIP,MEM,CTX }\end{array}$} & \multicolumn{6}{|c|}{$\mathrm{Ac}_{50}, \mathrm{Ac}_{48}, \mathrm{Ac}_{7}$} \\
\hline \multicolumn{16}{|c|}{$\begin{array}{l}\text { Keys: AN (Amikacin), CAZ (Ceftazidime), TZP (Piperacillin- tazobactam), SXT (Trimethoprim-sulphamethoxazole), CN (Gentamicin), IPM (Imipenem), LEV } \\
\text { (Levofloxacin), PRL (Piperacillin), CIP ( Ciprofloxacin), MEM (Meropenem), CTX (Cefotaxime). }\end{array}$} \\
\hline \multicolumn{16}{|c|}{ able 6: Antibacterial activity of essential oils against multi drug resistant wound isolates.* } \\
\hline selecte & 5 & 58 & 9 & 10 & 31 & 32 & 49 & 11 & 12 & 27 & 28 & 30 & 7 & 48 & 50 \\
\hline 1.Lemon oil & $18 \pm 1$ & $18 \pm 1$ & $15 \pm 0$ & $18 \pm 1$ & $15 \pm 1$ & $15 \pm 1$ & $16 \pm 1$ & $13 \pm 1$ & $14 \pm 1$ & $14 \pm 0$ & $13 \pm 1$ & $13 \pm 1$ & $0 \pm 0$ & $0 \pm 0$ & $0 \pm 0$ \\
\hline 2.Cinnamon oil & $33 \pm 1$ & $39 \pm 1$ & $25 \pm 1$ & $35 \pm 2$ & $37 \pm 1$ & $31 \pm 1$ & $24 \pm 1$ & $27 \pm 1$ & $30 \pm 1$ & $24 \pm 1$ & $31 \pm 2$ & $25 \pm 1$ & $35 \pm 2$ & $38 \pm 2$ & $35 \pm 1$ \\
\hline 3.Garlic oil & $0 \pm 0$ & $0 \pm 0$ & $0 \pm 0$ & $0 \pm 0$ & $0 \pm 0$ & $0 \pm 0$ & $0 \pm 0$ & $0 \pm 0$ & $0 \pm 0$ & $0 \pm 0$ & $0 \pm 0$ & $0 \pm 0$ & $0 \pm 0$ & $0 \pm 0$ & $0 \pm 0$ \\
\hline 4.Caraway oil & $17 \pm 0$ & $18 \pm 1$ & $13 \pm 1$ & $13 \pm 1$ & $15 \pm 1$ & $17 \pm 1$ & $13 \pm 0$ & $0 \pm 0$ & $0 \pm 0$ & $0 \pm 0$ & $0 \pm 0$ & $0 \pm 0$ & $14 \pm 1$ & $17 \pm 1$ & $18 \pm 1$ \\
\hline 5.Peppermint oil & $25 \pm 1$ & $29 \pm 1$ & $17 \pm 1$ & $20 \pm 1$ & $18 \pm 1$ & $18 \pm 1$ & $18 \pm 1$ & $15 \pm 1$ & $15 \pm 1$ & $17 \pm 1$ & $16 \pm 1$ & $17 \pm 1$ & $17 \pm 1$ & $17 \pm 1$ & $22 \pm 1$ \\
\hline 6.Tea tree oil & $24 \pm 1$ & $24 \pm 1$ & $20 \pm 1$ & $22 \pm 1$ & $20 \pm 1$ & $21 \pm 1$ & $20 \pm 1$ & $16 \pm 1$ & $16 \pm 1$ & $16 \pm 1$ & $16 \pm 1$ & $16 \pm 1$ & $19 \pm 1$ & $25 \pm 1$ & $21 \pm 1$ \\
\hline 7.Geranium oil & $0 \pm 0$ & $13 \pm 1$ & $0 \pm 0$ & $0 \pm 0$ & $0 \pm 0$ & $0 \pm 0$ & $0 \pm 0$ & $0 \pm 0$ & $0 \pm 0$ & $0 \pm 0$ & $0 \pm 0$ & $0 \pm 0$ & $0 \pm 0$ & $0 \pm 0$ & $0 \pm 0$ \\
\hline 8.Thyme oil & $40 \pm 1$ & $40 \pm 2$ & $21 \pm 1$ & $30 \pm 1$ & $33 \pm 1$ & $33 \pm 2$ & $22 \pm 1$ & $20 \pm 1$ & $20 \pm 1$ & $23 \pm 1$ & $29 \pm 1$ & $27 \pm 1$ & $27 \pm 1$ & $30 \pm 1$ & $29 \pm 1$ \\
\hline 9.Fennel oil & $14 \pm 1$ & $13 \pm 1$ & $0 \pm 0$ & $0 \pm 0$ & $0 \pm 0$ & $0 \pm 0$ & $0 \pm 0$ & $0 \pm 0$ & $0 \pm 0$ & $0 \pm 0$ & $0 \pm 0$ & $0 \pm 0$ & $0 \pm 0$ & $0 \pm 0$ & $0 \pm 0$ \\
\hline 10.Eucalyptus oil & $34 \pm 1$ & $39 \pm 1$ & $20 \pm 1$ & $28 \pm 1$ & $22 \pm 1$ & $22 \pm 1$ & $24 \pm 1$ & $22 \pm 1$ & $20 \pm 1$ & $20 \pm 1$ & $20 \pm 1$ & $19 \pm 1$ & $26 \pm 1$ & $30 \pm 1$ & $23 \pm 1$ \\
\hline 11.Clove oil & $25 \pm 2$ & $25 \pm 1$ & $19 \pm 1$ & $22 \pm 1$ & $28 \pm 1$ & $25 \pm 1$ & $21 \pm 1$ & $0 \pm 0$ & $0 \pm 0$ & $11 \pm 0$ & $0 \pm 0$ & $13 \pm 1$ & $25 \pm 1$ & $32 \pm 2$ & $24 \pm 1$ \\
\hline 12.Olive oil & $0 \pm 0$ & $0 \pm 0$ & $0 \pm 0$ & $0 \pm 0$ & $0 \pm 0$ & $0 \pm 0$ & $0 \pm 0$ & $0 \pm 0$ & $0 \pm 0$ & $0 \pm 0$ & $0 \pm 0$ & $0 \pm 0$ & $0 \pm 0$ & $0 \pm 0$ & $0 \pm 0$ \\
\hline 13.Camphor oil & $13 \pm 1$ & $18 \pm 1$ & $11 \pm 1$ & $14 \pm 1$ & $17 \pm 1$ & $14 \pm 1$ & $15 \pm 1$ & $0 \pm 0$ & $0 \pm 0$ & $15 \pm 1$ & $15 \pm 1$ & $13 \pm 1$ & $15 \pm 1$ & $16 \pm 1$ & $18 \pm 1$ \\
\hline 14.Anise oil & $0 \pm 0$ & $0 \pm 0$ & $0 \pm 0$ & $0 \pm 0$ & $0 \pm 0$ & $0 \pm 0$ & $0 \pm 0$ & $0 \pm 0$ & $0 \pm 0$ & $0 \pm 0$ & $0 \pm 0$ & $0 \pm 0$ & $0 \pm 0$ & $0 \pm 0$ & $0 \pm 0$ \\
\hline 15.Orange oil & $14 \pm 1$ & $14 \pm 0$ & $11 \pm 0$ & $14 \pm 0$ & $17 \pm 1$ & $14 \pm 1$ & $15 \pm 1$ & $0 \pm 0$ & $0 \pm 0$ & $0 \pm 0$ & $0 \pm 0$ & $0 \pm 0$ & $18 \pm 1$ & $15 \pm 1$ & $13 \pm 1$ \\
\hline 16.Dill oil & $18 \pm 1$ & $20 \pm 1$ & $13 \pm 1$ & $0 \pm 0$ & $17 \pm 1$ & $15 \pm 1$ & $15 \pm 1$ & $0 \pm 0$ & $0 \pm 0$ & $0 \pm 0$ & $0 \pm 0$ & $0 \pm 0$ & $0 \pm 0$ & $20 \pm 1$ & $0 \pm 0$ \\
\hline 17.Ginger oil & $20 \pm 1$ & $19 \pm 0$ & $0 \pm 0$ & $0 \pm 0$ & $17 \pm 1$ & $0 \pm 0$ & $0 \pm 0$ & $0 \pm 0$ & $0 \pm 0$ & $0 \pm 0$ & $0 \pm 0$ & $0 \pm 0$ & $13 \pm 1$ & $0 \pm 0$ & $0 \pm 0$ \\
\hline 18.Moringa oil & $0 \pm 0$ & $0 \pm 0$ & $0 \pm 0$ & $0 \pm 0$ & $0 \pm 0$ & $0 \pm 0$ & $0 \pm 0$ & $0 \pm 0$ & $0 \pm 0$ & $0 \pm 0$ & $0 \pm 0$ & $0 \pm 0$ & $0 \pm 0$ & $0 \pm 0$ & $0 \pm 0$ \\
\hline 19. Rose mary oil & $14 \pm 1$ & $14 \pm 1$ & $0 \pm 0$ & $0 \pm 0$ & $13 \pm 0$ & $14 \pm 1$ & $13 \pm 1$ & $0 \pm 0$ & $0 \pm 0$ & $0 \pm 0$ & $0 \pm 0$ & $0 \pm 0$ & $0 \pm 0$ & $16 \pm 1$ & $17 \pm 1$ \\
\hline
\end{tabular}

$50 \mu \mathrm{l}$ of different essential oils were pipetted into Muller Hinton agar plates seeded with $24 \mathrm{~h}$ old cultures of burn wound isolates and incubated for $24 \mathrm{~h}$ at $37^{\circ} \mathrm{C}$.

* All data represented are means of two experiments \pm SE.

Also, Hili et al. (1997) and Singh et al. (2007) recorded high antibacterial activity of cinnamon and thyme oils against $E$. coli. Other studies reported moderate activity of tea trees and eucalyptus oils (Schelz et al., 2006).

Table 7: chemical composition of cinnamon bark essential oil as identified by GC/MS analysis.

\begin{tabular}{lllc}
\hline Peak & Retention time & Compounds & \% of relative content \\
\hline 1 & 10.10 & $\alpha$-Pinene & 2.99 \\
2 & 10.90 & Camphene & 0.58 \\
3 & 11.75 & Sabinene & 2.21 \\
4 & 13.94 & $1,8-$ - ineole & 9.12 \\
5 & 19.01 & endo-Borneol & 0.44 \\
6 & 19.50 & Terpinen-4-ol & 2.61 \\
7 & 20.10 & $\alpha$-Terpineol & 3.23 \\
8 & 23.69 & Cinnamaldehyde & 60.78 \\
9 & 26.30 & $\alpha-C o p a e n e$ & 0.51 \\
10 & 27.43 & trans- $\alpha$-Bergamotene & 0.45 \\
11 & 27.71 & trans-Caryophyllene & 0.71 \\
12 & 28.73 & Cinnamyl acetate & 10.39 \\
13 & 30.90 & $\alpha-M u u r o l e n e$ & 0.46 \\
14 & 32.72 & ë-Cadinene & 0.52 \\
15 & 34.42 & Caryophyllene oxide & 0.39 \\
16 & 34.79 & tau--Muurolol & 0.52 \\
17 & 34.92 & $\alpha-C a d i n o l$ & 0.37 \\
Total identified compounds & 97.99 \\
\hline
\end{tabular}

Cinnamon oil, thyme oil and eucalyptus oil were found to be the most active oils against P.aeruginosa isolates followed by peppermint oil and tea tree oil, this result was almost similar to that described by Deans and Ritchie (1987), El-Shouny and Magaam (2009) and Dahiya and Purkayasth (2012). Data presented in Table (7) shows GC/MS analysis of cinnamon bark essential oils. It indicated that cinnamaldehyde $(60.78 \%)$ was the major constituent. This findigs are quite similar to that reported by El-Baroty et al. (2010) and Boniface et al. (2012). The antibacterial activity of cinnamon essential oil may be due to the presence of the carbonyl group on cinnamaldehyde that may bind to proteins and interfere with the function of bacterial amino acid decarboxylase (Wendakoon \& Sakaguchi, 1993 and 1995).

Results in Table (8) shows GC/MS of thyme essential oil which identified eleven chemicals as constituents; of these $\rho$ cymene and thymol were the main constituents $(83.1 \%)$. This result is in agreement with that reported by Burt (2004), he found that thyme oil contained of $10 \%-64 \%$ thymol and $10 \%-56 \%$ pcymene. p-cymene has a high affinity for membranes and causes membrane expansion and affect the membrane potential of intact cells (Ultee et al., 2002).

Thymol are able to disintegrate the outer membrane of gram-negative bacteria, releasing lipopolysaccharides (LPS) and increasing the permeability of the cytoplasmic membrane to ATP (Helander et al., 1998). 
Table 8: chemical composition of thyme essential oil as identified by GC/MS analysis

\begin{tabular}{lllc}
\hline Peak & Retention time & Compounds & $\begin{array}{c}\text { \% of relative } \\
\text { content }\end{array}$ \\
\hline 1 & 10.64 & a-pinene & 0.41 \\
2 & 11.20 & Camphene & 0.43 \\
3 & 14.65 & p-cymene & 50.14 \\
4 & 15.67 & c-Terpinene & 5.21 \\
5 & 17.28 & Linalool & 1.69 \\
6 & 18.71 & Camphor & 0.86 \\
7 & 19.70 & 1-Borneol & 4.66 \\
8 & 20.06 & 4-Terpineol & 0.63 \\
9 & 24.73 & Thymol & 32.9 \\
10 & 28.27 & trans-Caryophyllene & 1.42 \\
11 & 33.28 & Caryophyllene oxide & 1.28 \\
Total identified compounds & & 99.63 \\
\hline
\end{tabular}

\section{CONCLUSION}

Burn patients were most commonly infected with $P$. aeruginosa and $S$. aureus. The majority of these isolates are found to be multidrug resistant. A burn unit-specific nosocomial infection surveillance system may be introduced to reduce the incidence of multidrug resistant infections among burn patients, and for selecting appropriate antimicrobial agents. The obtained results indicate that cinnamon and thyme oils could be a promising an alternative medicine for the treatment of burn wound infections.

\section{REFERENCES}

Abbas HA, El-Masry EM, Shaker GH, Mohsen I. Bacterial etiology and antimicrobial resistance of burn wound infections in a burn Hehia general hospital in Egypt. Int J of Bio \&Pharm Research, 2013; 4(12):1251-1255.

Agnihotri N, Gupta V, Joshi R. Aerobic bacterial isolates from burn wound infections and their antibiograms - a five year study. Burns, 2004; 30:241-243.

Al-Akayleh T. Invasive burn wound infection. Ann Burns and Fire Disasters, 1999; 12:204-206.

Altoparlak U, Erol S, Akcay MN, Celebi F, Kadanali A. The time-related changes of anti-microbial resistance patterns and predominant bacterial profiles of burn wounds and body flora of burned patients. Burns, 2004; 30:660-664.

Arslan E, Dalay C, Yavuz M, Göcenler L, Acartürk S. Gramnegative bacterial surveillance in burn patients. Ann Burns and Fire Disasters, 1999; 12:81-83.

Aruna B, Jitendra S, Anjali P, Shobha G. Bacteriological profile of burns, in tertiary care referral center, bangalore. Pharmaco, 2010; 1:556-560.

Atoyebi A, Sowemimo A, Odugbemi T. Bacterial flora of burn wounds in Lagos, Nigeria: a prospective study. Burns, 1992; 18(6):448 451

Bakkali F, Averbeck S, Averbeck D, Idaomar M. Biological effects of essential oils-a review. Food Chem Toxicol, 2008; 46(2):446-75.

Baser KHC, Buchbauer G. 2010. Handbook of Essential Oils Science,Technology and Applications. Boca Raton, U.S.A: CRC Press.

Bauer AW, Kirby WM, Sherris JC, Turck M. Antibiotic susceptibility testing by a standardized single disk method. Am J Clin Pathol, 1966; 45:493-496.

Bayram Y, Parlak M, Aypak C, Bayram İ. Three-year Review of Bacteriologi- -ological Profile and Antibiogram of Burn Wound Isolates in Van,Turkey. Int J of med sci, 2013; 10(10):19-23.

Bhat V, Vasaikar S. Bacteriological profile and antibiogram of aerobic burn wound isolates in Mthatha, Eastern Cape, South Africa. South Afr J Epidemiol Infect, 2010; 25(4):16-19.

Boniface Y, Philippe S, De Lima HR, Pierre NJ, Alain AG, Fatiou $\mathrm{T}$, Dominique $\mathrm{S}$. Chemical composition and Antimicrobial activities of Cinnamomum zeylanicum Blume dry Leaves essential oil against Food-borne Pathogens and Adulterated Microorganisms. Int Research J of Bio Sci, 2012; 1(6):18-25

Burt S. "Essential oils: Their antibacterial properties and potential applications in foods." Int J of Food Microbio, 2004; 94(3):223253.

Church D, Elsayed S, Reid O, Winston B, Lindsay R. Burn Wound Infections. Clin Microbio Rev, 2006; 19(2):403-434.

CLSI 2006. Performance Standards for Antimicrobial Disk Susceptibility Tests; Approved Standard-Ninth Edition. CLSI documnet M2-A9. Clinical and laboratory Standards Institute, Pennsylvania, USA.

CLSI 2014. Performance Standards for Antimicrobial Susceptibility Testing; Twenty-Fourth Informational Supplement. CLSI documnet M10-S24. Clinical and laboratory Standards Institute, Pennsylvania, USA

Cremer R, Ainaud P, Le Bever H, Faber N, Carsin H. Nosocomial infections in a burns unit. Results of a prospective study over a year. Ann Fr Anesth Reanim, 1996; 15(5):599-607.

Dash M, Misra P, Routaray S. Bacteriological profile and antibiogram of aerobic burn wound isolates in a tertiary care hospital, Odisha, India. Int J of med and medical sci, 2013; 3(5):460-463.

De Marcedo J, Santos B, Bacterial and fungal colonization of burn wounds. Mem Inst Oswaldo Cruz Rio de Janerio, 2005; 100(5):535539.

Deans SG, Ritchie G. Antimicrobial properties of plant essential oils. Int J food Microbiol, 1987; 5:165-180.

Ekrami A, Kalantar E. Bacterial infections in burn patients at a burn hospital in Iran. Indian J Med Res, 2007; 126:541-544.

El-Baroty S, Abd El-Baky HH, Farag R, Saleh MA. Characterization of antioxidant and antimicrobial compounds of cinnamon and ginger essential oils. Afri J of Biochem Research, 2010; 4(6):167174.

El-Shouny WA, Magaam S. Sensitivity of Multi-drug Resistant Pseudomonas aeruginosa Isolated from Surgical Wound-infections to Essential Oils and Plant Extracts. World J of Med Sci, 2009; 4 (2):104111.

Engelkirk P, Duben-Engelkirk J. 2008. Laboratory Diagnosis Of Infectious Diseases. Philadelphia, USA: Lippincott Williams and Wilkins.

Guggenheim M, Zbinden R, Handschin AE, Gohritz A, Altintas MA, Giovanoli P. Changes in bacterial isolates from burn wounds and their antibiograms: A 20 year study (1986-2005). Burns, 2009; 35:553560 .

Helander IM, Alakomi HL, Kala KL, Sandholm TM, Pol I, Smid EJ, Gorris L, GM, Wright AV. Characterization of the action of selected essential oil components on Gram-negative bacteria. J of Agri and Food Chem, 1998; 46:3590-3595.

Hili P, Evans CS, Veness RG. Antimicrobial action of essential oils: The effect of dimethylsulphoxide on the activity of cinnamon oil. Lett Appl Microbiol, 1997; 24:269-275.

Husain T, Karim N, Tajuri S. Analysis of infection of a burn ward. Bums, 1989; 15(5):299-302.

Igumbor E, Gwanzura L, Chirara M, Obi C, Muza D, Chihara M. Antibiotic sensitivity and plasmid profiles of Pseudomonas aeruginosa. Cent Afr J Med, 2001; 46(11):296-300.

Imran M, Faheem M, Aslam V, Hakeem A, Rehman I, Shah A. Wound infections and culture sensitivity pattern in paediatric burn patients. JPMI, 2007; 23(4): 304-308.

Janssen AM, Chin NLJ, Scheffer JJC. Screening for antimicrobial activity of some essential oils by the agar overlay technique. Pharm World Sci, 1986; 8:289-292.

Kaushik R, Kumar S, Sharma R, Lal P. Bacteriology of burn wounds - the first three years in a new burns unit at the medical College Chandigarh. Burns, 2001; 27:595-59.

Kehinde AO, Ademola SA, Okesola AO, Oluwatosin OM, Bakare RA. Pattern of bacterial pathogens in burn wound infections in Ibadan, Nigeria. Ann Burns Fire Disasters, 2004; 17(1):12-15.

Komolafe OO, James J, Kalongolera L, Makoka M Bacteriological Of Burns at the Queen Elizabeth Centeral Hospital, Blantyre, Malawi. Burns, 2002; 29:235-238. 
Langeveld WT, Veldhuizen EJ, Burt SA. Synergy between essential oil components and antibiotics: a review. Crit Rev Microbiol 2013; 40(1):76-94.

Lari ARR, Alaghehbandan R, Akhlaghi L. Burn Wound Infections and Antimicrobial Resistance In Tehran Iran: An Increasing Problem. Ann of Burns and Fire Disast, 2005; 18(2):68-73.

Mahon RC, Lehman DC, Manuselis G. 2011. Text Book Of Diagnostic Microbiology. 4 th edn. Missouri, U.S.A: W B Saunders.

Manjula M, Priya D, Varsha G. Bacterial isolates from burn wound infections and their antibiograms: A eight-year study. Ind J Plas Surg, 2007; 40(1):25-28.

Mayhall CG. The Epidemiology of Burn Wound Infections:Then and Now. Clin Inf Dis, 2003; 37:543-550.

Mehta M, Dutta P, Gupta V. Bacterial isolates from burn wound infections and their antibiograms: A eight-year study. Ind J of plast surg, 2007; 40(1):25-28

Mohammedaman M, Alemseged A, Tsegaye S. Antimicrobial susceptibility pattern of bacterialisolates from wound infection and their sensitivity to alternative topical agents at Jimma University Specialized Hospital, South-West Ethiopia.Ann of Clin Microbio and Antimicrob, 2014; 13(14):1-10.

Montazeri E, Khosravi D, Feizabadi M, Hamed G, Khoramrooz S, Mehdi M, Enayatollah K, Darban D. The prevalence of methicillin resistant Staphylococcus aureus (MRSA) isolates with high-level mupirocin resistance from patients and personnel in a burn center. Burns, 2013; 39:650-654.

Nagesha CN, Shenoy KJ, Chandrashekar MR. Study of burn sepsis with special reference to Pseudomonas aeruginosa. J Ind Med Assoc, 1996; 94(6): 230-233.

Nagoba B, Deshmukh S, Wadher B, Pathan A. Bacteriological analysis of burn sepsis. Ind J Med Sci, 1999; 53:216-219.

Nakhla S, Sanders R. Microbiological aspects of burns at mount vernon hospital, UK. Burns, 1991; 17(4):309-312.

Nash RJ, Kato A, Yu CY, Fleet G. Iminosugars as therapeutic agents: recent advances and promising trends. Future Med Chem, 2011; $3: 1513-1521$.

Nasser S, Mabrouk A, Maher A. Colonization of burn wounds in Ain Shams university burn unit. Burns, 2003; 29(3):229-233.

Oncul O, Yksel F, Altunay H, Açikel C, Celiköz B, Cavuslu S. The evaluation of nosocomial infection during 1-year period in the burn unit of a training hospital in Istanbul, Turkey. Burns, 2002; 28:738-44.

Osbourn A. Preformed antimicrobial compounds and plant defense against fungal attack. Plant Cell, 1996; 8:1821-1831.

Ozumba U, Jiburum B. Bacteriology of burn wounds in Enugu,Nigeria. Burns, 2000; 26:178-180.

Pandit V, Gore A, Saileshwar N, Deodhar P. Laboratory data from the surveillance of a burns ward for the detection of hospital infection. Burns, 1993; 19(1):52-55.

Ramakrishnan MK, Sankar J, Venkatraman J, Ramesh J. Infection in burn patients-experience in a tertiary care hospital. Burns, 2006; 32:594-596.

Rajput A, Singh K, Kumar V, Sexena R, Singh R. Antibacterial resistance pattern of aerobic bacteria isolates from burn patients in tertiary care hospital. Biomed Res, 2008; 19(1):1-4. 24:347-349.

Revathi G, Puri J, Jain K. Bacteriology of burns. Burns, 1998;

Rezaei E, Safari H, Naderinasab M, Aliakbarian H. Common pathogens in burn wound and changes in their drug sensitivity. Burns, 2011; 37:805-807.

Samuel SO, Kayode OO, Musa OI, Nwigwe GC, Aboderin AO, Salami TAT, Taiwo SS. Nosocomial infections and the challenges of control in developing countries. Afri J clin exp Microbio, 2010; 11(2):102-110.

Schelz Z, Molnar J, Hohmann J. Antimicrobial and antiplasmid activities of essential oils. Fitoterapia, 2006; 77:279-285.

Shankowsky A, Callioux S, Tredget E. North America survey of hydrotherapy in modern burn care. J Burn Care Rehabil, 1994; 15(2):143$6 \mathrm{v}$

Singh G, Maurya S, Delampasona MP. A comparison of chemical, antioxidant and antimicrobial studies of cinnamon leaf and bark volatile oils, oleoresins and their constituents. Food Chem Toxicol, 2007; 45:1650-1661.

Singh NP, Goyal R, Manchanda V, Das S, Kaur I, Talwar V. Changing trends in bacteriology of burns in the burn unit, Delhi, India. Burns, 2003; 29:129-132.

Song W, Lee KM, Kang HJ, Shin DH, Kim DK. Microbiologic aspects of predominant bacteria isolated from the burn patients Korea. Burns, 2001; 27(2):136-139.

Taneja N, Emmanuel R, Chari PS, Sharma M. A prospective study of hospital-acquired infections in burn patients at atertiary care referral centre in north India. Burns, 2004; 30(7):665-669.

Ultee A, Bennik MHJ, Moezelaar R. The phenolic hydroxyl group of carvacrol is essential for action against the food-borne pathogen Bacillus cereus. Appl Environ Microbiol, 2002; 68:1561-1568

Vaijnath, DA. Bacteriological profile of burn wound infecions and its antibiogram. 2013

Vindenes $\mathrm{H}$, Bjerknes R. Microbial colonization of large wounds. Burns, 1995; 21:575-579.

Wendakoon C, Sakaguchi M. Inhibition of amino acid decarboxylase activity of Enterobacter aerogenes by active components in spices. J Food Prot, 1993;1995; 58:280-283.

Xu C, Wen-Kui W, Li-Zhong H, Ying L, Hong Z, Jin T, QingZhong L, YuChan H, Yu-Xing N. Epidemiological and Genetic Diversity of Staphylococcus aureus Causing Bloodstream Infection in Shanghai. Plos one, 2013; 8(9):1-7.

Yousef RT, Tawil GG. Antimicrobial activity of volatile oils. Pharmazie, 1980; 35:698-701.

\section{How to cite this article:}

Mabrouk MI, El-Hendawy HH, Basha AM, Saleh NM. Prevalence, antibiotic and oil resistance pattern of some bacterial isolates from burns. J App Pharm Sci, 2016; 6 (06): 123-130. 